\title{
High chlamydia positivity rates in Indigenous people attending Australian sexual health services
}

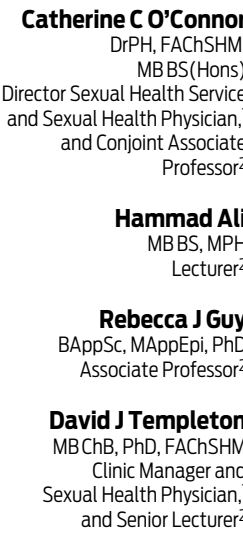

Christopher K Fairley PhD, FRACP, FAChSHM Director, ${ }^{3}$ and Professor

Marcus Y Chen MBBS, PHD, FAChSHM Sexual Health Physician ${ }^{3}$

Bridget M Dickson

Lewis J Marshall MBBS, FAChSHM, FAFPHM Head, ${ }^{6}$ and Adjunc Associate Professor ${ }^{7}$

Andrew E Grulich MBBS, PhD, MScEpi Professor and Head of HIV Epidemiology an Prevention Program²

Margaret E Hellard MBBS, FRACP, PHD Professor and Head of Centre for Population Health ${ }^{8}$

John M Kaldo PhD
Public Professor and Head of Public Health Intervention Research Group ${ }^{2}$

Basil Donovan MBBS, MD, FAChSHM Professor and Head of Sexual Health Program, ${ }^{2}$ and Sexual Health Physician 9

James S Ward

Deputy Director

IRPA Sexual Health Sydney Local Health District, Sydney, NSW.

2 Kirby Institute, University of

New South Wales

Sydney, NSW

3 Melbourne Sexual Health Centre, Melbourne, VIC.

4 Melbourne School

of Population and Global Health

University of Melbourne

Melbourne, VIC

5 CaraData Pty Ltd Brisbane, QLD.
G enital Chlamydia trachomatis infection (chlamydia) is the most common notifiable infection in Australia, with 80809 new notifications reported in 2011 and notifications increasing steadily over 20 years. ${ }^{1}$ Chlamydia notification rates are highest in Aboriginal and Torres Strait Islander (hereafter Indigenous) people, ${ }^{2,3}$ followed by young people ${ }^{2}$ and men who have sex with men.4,5 Indigenous people make up $2.5 \%$ of Australia's population 6 yet account for $9 \%$ of chlamydia diagnoses each year, with notification rates increasing by $26 \%$ between 2007 and $2011 .^{3}$ Indigenous people are one of the priority populations in the National Sexually Transmissible Infections Strategy. ${ }^{7}$

Using notification data to assess trends has a number of limitations. First, Indigenous status is very incomplete in notifications from several jurisdictions; for example, in New South Wales, Queensland and the Australian Capital Territory, less than $50 \%$ of chlamydia notifications had Indigenous status recorded. 3,8 Second, notifications are highly correlated with increasing testing rates. 2,9 Third, some jurisdictions have introduced remote and regional screening programs targeting Indigenous people, which contribute to higher notifications. ${ }^{8}$

Understanding chlamydia trends in Indigenous populations requires diagnoses to be assessed in the context of testing patterns. Australia has a widely dispersed network of publicly funded sexual health services that focus on priority populations, including young sexually active heterosexuals, men who have sex with men, sex workers and Indigenous people. ${ }^{7}$ We assessed the attendance, chlamydia testing and positivity rates among Indigenous people attending sexual health services participating in a national sentinel surveillance network.

\section{Methods}

\section{Sentinel surveillance system}

The Australian Collaboration for Chlamydia Enhanced Sentinel

Abstract

Objective: To assess the clinical epidemiology of chlamydia among Aboriginal and Torres Strait Islander (Indigenous) people attending sexual health services around Australia.

Design: Retrospective analysis of routine demographic, behavioural and clinical data, between 1 January 2006 and 31 December 2011.

Setting: 18 sexual health services in major cities and regional centres in five jurisdictions.

Main outcome measures: Attendance, chlamydia testing and positivity rates in patients visiting for the first time, and factors associated with chlamydia positivity.

Results: Of 168729 new patients, 7103 (4.2\%) identified as Indigenous, of whom $74.3 \%$ were tested for chlamydia. Chlamydia positivity was $17.0 \%$ in Indigenous women (23.3\% in 15-19-year-olds and $18.9 \%$ in 20-24-year-olds) and $17.3 \%$ in Indigenous men (20.2\% in 15-19-year-olds and $24.2 \%$ in 20-24-year-olds). There was an increasing trend in chlamydia positivity in Indigenous women from 2006 to 2011 ( $P$ for trend = 0.001), but not in Indigenous men. In Indigenous women, factors independently associated with positivity were: younger age, being heterosexual, living in Queensland and attending the service in 2010. In Indigenous men, independent factors associated with chlamydia positivity were younger age, being heterosexual, having sex only in Australia and living in a regional area.

Conclusion: The high and increasing chlamydia positivity rates highlight the need for enhanced prevention and screening programs for Indigenous people.

Surveillance (ACCESS) sexual health service network consists of 25 participating sexual health services (44 clinics) in all jurisdictions except South Australia, which was unable to participate due to database compatibility issues. ${ }^{10}$ Sixteen of these services are in major cities and nine are in regional areas. All test for chlamydia using nucleic acid amplification tests.

\section{Data collection}

The methods of the ACCESS project are published elsewhere. ${ }^{10}$ Briefly, retrospective, de-identified, line-listed, demographic and chlamydia testing data on all new patients were extracted from patient management systems by using standardised extraction software.

\section{Analysis}

Data were included from 18 sexual health services ( 35 clinic sites) that were able to contribute data from 1 January 2006 to 31 December 2011. We calculated the chlamydia testing and positivity rates among new patients. Only one positive test per patient was counted. All outcomes were stratified by the patients' demographics and sexual behaviour. Place of residence was based on postcode, using a modified version of the Australian Bureau of Statistics' (ABS) Australian Statistical Geography Standard Remoteness Structure.11 Inner and outer regional areas were combined into regional Australia and, likewise, remote and very remote areas were combined into remote Australia. The proportions of Indigenous people in each jurisdiction were taken from the ABS National Regional Profile 2006-2010.12

We compared attendance among Indigenous men and women, and positivity among both Indigenous and non-Indigenous men and women separately. We used a mixed-method random effects model for multivariate analysis to account for clustering at the clinic level. The initial model included all variables and backward elimination was used until only the variables that were significant remained in the model. Only the variables that were significant in the final model are reported in the results and tables.

Odds ratios with 95\% confidence intervals were reported in the results 
6 Sexual Health Service, Fremantle Hospital, Perth, WA.

7 University of Notre Dame Fremantle, Perth, WA.

8 Centre for Population Health, Burnet Institute, Melbourne, VIC.

9 Sydney Sexual Health Centre, Sydney, NSW.

10 Baker IDI Heart and Diabetes Institute, Alice Springs, NT.

catherine.oconnor@ unsw.edu.au

MJA 2014; 200: 595-598 doi: 10.5694/mjal3.10875 1 Proportion of first-time patients attending sexual health services in 2006-2011
who were Indigenous, by sex

\begin{tabular}{|c|c|c|}
\hline Client characteristics & Indigenous men ( $n=3158$ ) & Indigenous women $(n=3945)$ \\
\hline All & $3.4 \%$ & $5.3 \%$ \\
\hline \multicolumn{3}{|l|}{ Jurisdiction (clinic) } \\
\hline Vic & $0.8 \%$ & $0.7 \%$ \\
\hline NSW & $3.3 \%$ & $4.6 \%$ \\
\hline Qld & $7.5 \%$ & $10.6 \%$ \\
\hline WA & $2.6 \%$ & $4.9 \%$ \\
\hline NT & $7.4 \%$ & $11.4 \%$ \\
\hline \multicolumn{3}{|l|}{ Age group (years) } \\
\hline $15-19$ & $13.6 \%$ & $12.0 \%$ \\
\hline $20-24$ & $3.0 \%$ & $3.2 \%$ \\
\hline $25-29$ & $1.9 \%$ & $2.7 \%$ \\
\hline $30-34$ & $2.3 \%$ & $3.6 \%$ \\
\hline $35+$ & $2.5 \%$ & $4.9 \%$ \\
\hline \multicolumn{3}{|l|}{ Location of residence } \\
\hline Major city & $1.2 \%$ & $1.6 \%$ \\
\hline Regional & $10.4 \%$ & $13.0 \%$ \\
\hline Remote & $22.7 \%$ & $31.8 \%$ \\
\hline
\end{tabular}

NSW = New South Wales. NT = Northern Territory. Qld = Queensland. Vic = Victoria. WA = Western Australia.

and were calculated in Stata version 12 (StataCorp). We also conducted a trends analysis over time (2006-2011) for attendance and positivity rates by using a $\chi^{2}$ test for trend.

\section{Ethics}

Ethics approval for the ACCESS sexual health network was granted by the Human Research Ethics Committees of St Vincent's Hospital, Sydney, the University of New South Wales and the local committees overseeing each of the sexual health services.

\section{Results}

A total of 179276 patients attended the sexual health services for the first time between 2006 and 2011. Of these, 10110 were excluded because of missing Indigenous status and 437 patients were excluded because of other missing or inconsistent data, leaving 168729 patients for analysis: 7103 (4.2\%) were Indigenous and 161626 (95.8\%) were non-Indigenous. Proportionately, there were more Indigenous women than non-Indigenous women $(55.5 \%$ v $44.0 \%, P<0.001)$. The median age of Indigenous women was 21 years (interquartile range [IQR], 17-30 years) compared with 25 years (IQR, 21-32 years) in non-Indigenous women. For Indigenous men, the median age was 23 years (IQR, 18-33 years) compared with 28 years (IQR, 23-38 years) for non-Indigenous men.

Of all first-time patients, the proportion who were Indigenous varied according to patient demographics and clinic location (Box 1). Among women, the proportion who were Indigenous was highest in services located in the Northern Territory (11.4\%) and Qld (10.6\%), in 15-19-year-olds (12.0\%), and in women living in remote (31.8\%) and regional areas (13.0\%) (Box 1). Among men, the proportion of first-time patients who were Indigenous was highest in services located in Qld (7.5\%) and NT (7.4\%), in 15-19-year-olds (13.6\%), and in men living in remote $(22.7 \%)$ and regional $(10.4 \%)$ areas. The proportion of new female patients who were Indigenous increased from $4.7 \%$ in 2006 to $5.5 \%$ in 2011 ( $P$ for trend $<0.01$ ), but there was no increase in the proportion of Indigenous men (3.6\% in both years; $P$ for trend $=0.8$ )

\section{Testing rates}

Chlamydia testing rates across the study were high. Testing rates among Indigenous patients were lower than among non-Indigenous patients (74.3\% v 79.1\%, $P<0.001)$.

\section{Positive chlamydia tests}

Overall, Indigenous patients contributed $7.4 \%$ of positive chlamydia tests:
$12.0 \%$ in NT, $16.2 \%$ in Qld, $4.7 \%$ in NSW, 5.9\% in Western Australia and less than $1 \%$ in Victoria.

\section{Chlamydia positivity rates in women}

Chlamydia positivity rates were significantly higher in Indigenous women than in non-Indigenous women overall $(17.0 \%$ v $9.4 \%, P<0.001)$, and in Qld (23.7\% v $11.8 \%, P<0.001)$, WA $(28.2 \%$ $\mathrm{v} 11.8 \%, P<0.001)$ and NSW $(11.2 \% \mathrm{v}$ $8.3 \%, P<0.001)$. Among Indigenous women, positivity rates were higher than in non-Indigenous women in all age groups, and increased in both groups with decreasing age (Box 2 and Appendix 1; all Appendices online at mja.com.au). Positivity rates were higher in Indigenous than non-Indigenous women in regional areas (17.8\% v $11.5 \%, P<0.001)$ and in major cities $(13.4 \%$ v $8.6 \%, P<0.001)$, but they were similar in remote areas $(17.3 \% \mathrm{v}$ $12.0 \%, P=0.33$ ).

During the study period there was a trend to increasing chlamydia positivity in both Indigenous ( $P$ for trend $=0.01$ ) and non-Indigenous women $(P$ for trend $=0.01$ ).

On multivariate analysis, higher chlamydia positivity in Indigenous women was associated with younger age, being heterosexual, living in Qld and attending a sexual health service in 2010 (Box 2 and Appendix 1). These variables were significant in the final model after backward elimination.

\section{Chlamydia positivity rates in men}

Chlamydia positivity rates were significantly higher in Indigenous men than non-Indigenous men overall (17.3\% v 9.7\%, $P<0.001)$ and in all states and territories except Vic (Box 2 and Appendix 2). Positivity was higher in Indigenous than non-Indigenous men in all age groups $(P<0.05$ for all), although both groups yielded the highest positivity in 20-24-yearolds. Positivity rates were higher in Indigenous than non-Indigenous men living in regional areas $(20.0 \% \mathrm{v} 12.4 \%$, $P<0.001)$ but they were similar in men living in major cities $(10.0 \% \mathrm{v} 9.0 \%$, $P=0.43)$ and remote areas $(12.5 \% \mathrm{v}$ $9.2 \%, P=0.55)$. During the study period, there was no change in chlamydia positivity in Indigenous men ( $P$ for trend $=0.23$ ) but an increasing trend in non-Indigenous men $(P$ for trend $=0.01$ ). 
2 Factors associated with chlamydia in Indigenous and non-Indigenous people, 2006-2011

\begin{tabular}{|c|c|c|c|c|c|c|c|c|}
\hline \multirow[b]{2}{*}{$\begin{array}{l}\text { Client } \\
\text { characteristics }\end{array}$} & \multicolumn{2}{|c|}{$\begin{array}{l}\text { Indigenous women who tested } \\
\text { positive to chlamydia }(n=479)\end{array}$} & \multicolumn{2}{|c|}{$\begin{array}{l}\text { Non-Indigenous women who tested } \\
\text { positive to chlamydia }(n=5219)\end{array}$} & \multicolumn{2}{|c|}{$\begin{array}{l}\text { Indigenous men who tested } \\
\text { positive to chlamydia }(n=427)\end{array}$} & \multicolumn{2}{|c|}{$\begin{array}{l}\text { Non-Indigenous men who tested } \\
\text { positive to chlamydia }(n=7043)\end{array}$} \\
\hline & $\begin{array}{l}\text { Chlamydia } \\
\text { positivity }\end{array}$ & $\begin{array}{l}\text { Adjusted OR } \\
(95 \% \mathrm{Cl})\end{array}$ & $\begin{array}{l}\text { Chlamydia } \\
\text { positivity }\end{array}$ & $\begin{array}{l}\text { Adjusted OR } \\
(95 \% \mathrm{CI})\end{array}$ & $\begin{array}{l}\text { Chlamydia } \\
\text { positivity }\end{array}$ & $\begin{array}{l}\text { Adjusted OR } \\
(95 \% \mathrm{Cl})\end{array}$ & $\begin{array}{l}\text { Chlamydia } \\
\text { positivity }\end{array}$ & $\begin{array}{l}\text { Adjusted OR } \\
(95 \% \mathrm{Cl})\end{array}$ \\
\hline All $(n=168729)$ & $17.0 \%$ & & $9.4 \%$ & & $17.3 \%$ & & $9.7 \%$ & \\
\hline \multicolumn{9}{|l|}{ Clinic jurisdiction } \\
\hline Vic* & $10.6 \%$ & 1 & $8.5 \%$ & $\dagger$ & $11.0 \%$ & $\dagger$ & $9.3 \%$ & $\dagger$ \\
\hline NSW & $11.2 \%$ & $0.87(0.45-1.71)$ & $8.3 \%$ & $\dagger$ & $10.6 \%$ & $\dagger$ & $8.4 \%$ & $\dagger$ \\
\hline Qld & $23.7 \%$ & $2.19(1.13-4.25)$ & $11.8 \%$ & $\dagger$ & $19.2 \%$ & $\dagger$ & $13.8 \%$ & $\dagger$ \\
\hline WA & $28.2 \%$ & $2.20(0.96-5.08)$ & $11.8 \%$ & $\dagger$ & $27.6 \%$ & $\dagger$ & $10.4 \%$ & $\dagger$ \\
\hline NT & $16.8 \%$ & $1.25(0.63-2.49)$ & $14.2 \%$ & $\dagger$ & $19.8 \%$ & $\dagger$ & $13.5 \%$ & $\dagger$ \\
\hline \multicolumn{9}{|l|}{ Age group (years) } \\
\hline 15-19 & $23.3 \%$ & $3.36(2.39-4.73)$ & $15.2 \%$ & $4.80(4.17-5.52)$ & $20.2 \%$ & $2.66(1.69-4.20)$ & $13.0 \%$ & $2.44(2.19-2.71)$ \\
\hline $20-24$ & $18.9 \%$ & $2.61(1.77-3.83)$ & $12.3 \%$ & $3.85(3.37-4.41)$ & $24.2 \%$ & $3.57(2.25-5.65)$ & $13.1 \%$ & $2.45(2.27-2.65)$ \\
\hline $25-29$ & $13.4 \%$ & $1.76(1.12-2.78)$ & $8.1 \%$ & $2.52(2.19-2.90)$ & $17.0 \%$ & $2.45(1.45-4.16)$ & $10.8 \%$ & $2.00(1.84-2.17)$ \\
\hline $30-34$ & $9.4 \%$ & $1.27(0.72-2.25)$ & $5.5 \%$ & $1.72(1.46-2.04)$ & $11.7 \%$ & $1.39(0.72-2.68)$ & $8.0 \%$ & $1.50(1.36-1.66)$ \\
\hline $35+*$ & $3.6 \%$ & 1 & $3.2 \%$ & 1 & $7.3 \%$ & 1 & $5.8 \%$ & 1 \\
\hline \multicolumn{9}{|c|}{ Sexual behaviour (past 12 months) } \\
\hline $\begin{array}{l}\text { Homosexual or } \\
\text { bisexual* }\end{array}$ & $11.7 \%$ & 1 & $7.7 \%$ & 1 & $10.0 \%$ & 1 & $7.9 \%$ & 1 \\
\hline Heterosexual & $18.7 \%$ & $2.15(1.58-2.92)$ & $9.9 \%$ & $1.26(1.09-1.45)$ & $20.1 \%$ & $2.56(1.64-4.00)$ & $10.7 \%$ & $1.27(1.19-1.35)$ \\
\hline No sex & $9.5 \%$ & $1.54(0.34-7.00)$ & $3.3 \%$ & $0.55(0.37-0.81)$ & $12.5 \%$ & $2.47(0.51-12.03)$ & $4.4 \%$ & $0.24(0.13-0.44)$ \\
\hline \multicolumn{9}{|l|}{ Place of residence } \\
\hline Major city* & $13.4 \%$ & $\dagger$ & $8.6 \%$ & $\dagger$ & $10.0 \%$ & 1 & $9.0 \%$ & $\dagger$ \\
\hline Regional & $17.8 \%$ & $\dagger$ & $11.5 \%$ & $\dagger$ & $20.0 \%$ & $1.87(1.24-2.82)$ & $12.4 \%$ & $\dagger$ \\
\hline Remote & $17.3 \%$ & $\dagger$ & $12.0 \%$ & $\dagger$ & $12.5 \%$ & $0.52(0.15-1.82)$ & $9.2 \%$ & $\dagger$ \\
\hline \multicolumn{9}{|l|}{ Sex work (current) } \\
\hline Yes & $7.6 \%$ & $\dagger$ & $5.6 \%$ & $0.80(0.71-0.90)$ & $16.0 \%$ & $\dagger$ & $6.3 \%$ & $0.69(0.51-0.93)$ \\
\hline No* & $18.1 \%$ & $\dagger$ & $10.8 \%$ & 1 & $18.2 \%$ & $\dagger$ & $9.3 \%$ & 1 \\
\hline \multicolumn{9}{|c|}{ Sex overseas (past 12 months) } \\
\hline Yes & $15.5 \%$ & $\dagger$ & $9.9 \%$ & $1.11(1.03-1.19)$ & $8.8 \%$ & $0.56(0.32-0.98)$ & $10.2 \%$ & $\dagger$ \\
\hline No* & $18.5 \%$ & $\dagger$ & $10.2 \%$ & 1 & $19.6 \%$ & 1 & $9.7 \%$ & $\dagger$ \\
\hline \multicolumn{9}{|l|}{ Year of first visit } \\
\hline 2006* & $14.4 \%$ & 1 & $9.1 \%$ & 1 & $15.8 \%$ & 1 & $9.6 \%$ & 1 \\
\hline 2007 & $15.3 \%$ & $1.16(0.78-1.73)$ & $8.4 \%$ & $\dagger$ & $12.4 \%$ & $\dagger$ & $8.8 \%$ & $0.89(0.81-0.99)$ \\
\hline 2008 & $13.1 \%$ & $0.91(0.61-1.35)$ & $9.1 \%$ & $\dagger$ & $20.5 \%$ & $\dagger$ & $9.3 \%$ & $0.94(0.86-1.04)$ \\
\hline 2009 & $16.7 \%$ & $1.16(0.80-1.69)$ & $9.2 \%$ & $\dagger$ & $17.1 \%$ & $\dagger$ & $10.1 \%$ & $1.03(0.94-1.13)$ \\
\hline 2010 & $22.0 \%$ & $1.60(1.11-2.29)$ & $10.1 \%$ & $\dagger$ & $21.1 \%$ & ${ }^{\dagger}$ & $10.4 \%$ & $1.05(0.96-1.15)$ \\
\hline 2011 & $19.8 \%$ & $1.40(0.97-2.03)$ & $10.3 \%$ & $\dagger$ & $16.2 \%$ & $\dagger$ & $10.0 \%$ & $0.98(0.90-1.08)$ \\
\hline
\end{tabular}

NSW $=$ New South Wales. NT = Northern Territory. OR = odds ratio. Qld = Queensland. Vic = Victoria. WA = Western Australia. $*$ Reference category. $\dagger$ The variable was not significant by backward elimination in the final model and is not included in the model.

On multivariate analysis, higher chlamydia positivity in Indigenous men was associated with younger age, being heterosexual and living in regional areas. Chlamydia positivity was lower in Indigenous men who reported having sex overseas (Box 2 and Appendix 2). These variables were significant in the final model after backward elimination.

\section{Discussion}

Over 7000 new Indigenous patients attended one of the participating sexual health services and the proportion who were Indigenous (4.2\%) was higher than the proportion of Indigenous people in the Australian population $(2.5 \%){ }^{6}$ There was a significant increasing trend in chlamydia positivity in Indigenous women as well as non-Indigenous women and men between 2006 and 2011, but not among Indigenous men. In Indigenous women, factors independently associated with a positive chlamydia test were younger age, being heterosexual, living in Qld and attending the service in 2010. In Indigenous men, independent factors were younger age, being heterosexual, living in a regional area, and having sex only in Australia.

The main strength of our study is that it reports on data from a national system of sexual health services, including five jurisdictions, alleviating concerns about using data from a single clinic or region. In addition, the demographic and behavioural data are much more comprehensive than what is available through the passive surveillance system. The ACCESS system has some limitations too. First, patients attending sexual health services are not representative of the general population, ${ }^{9}$ as they are more likely to seek 
care if they have symptoms or consider themselves at a risk of an infection; thus, the prevalence should be higher than in a general population sample. ${ }^{13}$ Second, some clinics still run on a paper-based medical record system and data have to be manually transferred into the database system. Sometimes busy clinicians may complete the paper-based record but forget to record it into the database system. Consequently, testing and positivity rates may be underestimated.

As has been seen in other clinical settings, ${ }^{14-18}$ chlamydia positivity rates were higher in Indigenous than nonIndigenous patients. Positivity was associated with younger age and being heterosexual, which has been attributed to both biological and behavioural factors. ${ }^{19-21}$ These findings reinforce the need to focus chlamydia prevention and screening strategies on young Indigenous people.

Surprisingly, chlamydia positivity rates were not as high in Indigenous patients living in remote Australia as found in some studies. ${ }^{14,17}$ There are no sexual health clinics in remote areas, so Indigenous people living in remote areas would usually only come in contact with sexual health services through outreach community screening of asymptomatic patients. By contrast, Indigenous people living in the major cities and regional Australia would have better access to sexual health clinics when they have symptoms. Also, in Indigenous men, recent sex overseas was associated with a lower chlamydia positivity rate. Overseas travel may be a marker of higher socioeconomic status and better access to health care. ${ }^{22}$

The increasing proportion of first visits by Indigenous women over time is encouraging. This is probably due to an increase in the service efficiencies and more strategic use of limited resources. ${ }^{7}$ Sexual health services have adopted a range of interventions, often involving information technology as a way to improve service quality while reducing costs. ${ }^{23}$ New service models need to be explored for chlamydia screening targeting young Indigenous people, such as outreach testing, ${ }^{24}$ express clinics ${ }^{23}$ and new technologies including point-of-care polymerase chain reaction testing, which allows a 90-minute result turnaround, increasing same-day testing and treatment. ${ }^{25}$ Indigenous people should remain a high priority for Australian sexual health services.

Acknowledgements: ACCESS is a collaboration between the Kirby Institute, the Burnet Institute, the National Serology Reference Laboratory, and the National Perinatal Epidemiology and Statistics Unit. The ACCESS project was funded by the Australian Government Department of Health and Ageing from 2007 to 2010. It is now funded by the health departments of NSW, Vic, NT and ACT. Margaret Hellard, Rebecca Guy and Bridget Dickson receive funding support from National Health and Medical Research Council fellowships. The Burnet Institute acknowledges the contribution to this work of the Victorian Operational Infrastructure Support Program. We thank all the sexual health services that provided data for ACCESS (Appendix 3 ). We thank Matthew Law, Professor and Program Head, and Handan Wand, Senior Lecturer, Biostatistics and Databases Program, Kirby Institute, University of New South Wales, who provided statistical advice.

Competing interests: No relevant disclosures. Received 28 Jun 2013, accepted 19 Feb 2014

1 Australian Government Department of Health. Introduction to the National Notifiable Diseases Surveillance System. Canberra; 2011. http:// www.health.gov.au/internet/main/publishing. nsf/content/cda-surveil-nndss-nndssintro.htm (accessed Apr 2014).

2 Graham S, Guy RJ, Donovan B, et al. Epidemiology of chlamydia and gonorrhoea among Indigenous and non-Indigenous Australians, 2000-2009. Med J Aust 2012; 197 : 642-646.

3 The Kirby Institute. Bloodborne viral and sexually transmitted infections in Aboriginal and Torres Strait Islander people: surveillance and evaluation report 2012. Sydney: The Kirby Institute, University of New South Wales. http://www.kirby.unsw.edu.au/ surveillance/2012-aboriginal-surveillancereport-hiv-viral-hepatitis-stis (accessed May 2013)

4 Jin F, Prestage GP, Mao L, et al. Incidence and risk factors for urethral and anal gonorrhoea and chlamydia in a cohort of HIV-negative homosexual men: the Health in Men Study. Sex Transm Infect 2007; 83: 113-119.

5 Lister NA, Smith A, Tabrizi S, et al. Screening for Neisseria gonorrhoeae and Chlamydia trachomatis in men who have sex with men at male-only saunas. Sex Transm Dis 2003; 30: 886-889.

6 Australian Bureau of Statistics. 2011 Census QuickStats. http://www.censusdata.abs.gov. au/census_services/getproduct/census/2011/ quickstat/0 (accessed Sep 2013).

7 Australian Department of Health. Second National Sexually Transmissible Infections Strategy 2010-2013. https://www.health.gov. au/internet/main/publishing.nsf/Content/ ohp-national-strategies-2010-sti (accessed May 2013).

8 Guy R, Ward JS, Smith KS, et al. The impact of sexually transmissible infection programs in remote Aboriginal communities in Australia: a systematic review. Sex Health 2012; 9: 205-212.

9 Ali H, Guy RJ, Fairley CK, et al. Understanding trends in genital Chlamydia trachomatis can benefit from enhanced surveillance: findings from Australia. Sex Transm Infect 2012; 88 : 552-557.

10 Guy RJ, Kong F, Goller J, et al. A new national chlamydia sentinel surveillance system in
Australia: evaluation of the first stage of implementation. Commun Dis Intell Q Rep 2010; 34: 319-328.

11 Australian Bureau of Statistics. Australian Statistical Geography Standard (ASGS) Remoteness structure. http://www.abs.gov. au/websitedbs/D3310114.nsf/home/Australi an+Statistical+Geography+Standard+(ASGS) (accessed May 2013).

12 Australian Bureau of Statistics. National regional profile 2007-2011. http://www. ausstats.abs.gov.au/ausstats/nrpmaps.nsf/ $\mathrm{NEW+GmapPages/national+regional+profile?o}$ pendocument (accessed Dec 2013).

13 Walker J, Fairley CK, Bradshaw CS, et al. The difference in determinants of Chlamydia trachomatis and Mycoplasma genitalium in a sample of young Australian women. BMC Infect Dis 2011; $11: 35$.

14 Garrow SC, Smith DW, Harnett GB. The diagnosis of chlamydia, gonorrhoea, and trichomonas infections by self obtained low vaginal swabs, in remote northern Australian clinical practice. Sex Transm Infect 2002; 78 : 278-281.

15 Lenton JA, Freedman E, Hoskin K, et al. Chlamydia trachomatis infection among antenatal women in remote far west New South Wales, Australia. Sex Health 2007; 4: 139-140.

16 Knox J, Tabrizi SN, Miller P, et al. Evaluation of self-collected samples in contrast to practitioner-collected samples for detection of Chlamydia trachomatis, Neisseria gonorrhoeae, and Trichomonas vaginalis by polymerase chain reaction among women living in remote areas. Sex Transm Dis 2002; 29: 647-654.

17 Miller PJ, Torzillo PJ, Hateley W. Impact of improved diagnosis and treatment on prevalence of gonorrhoea and chlamydial infection in remote Aboriginal communities on Anangu Pitjantjatjara Lands. Med J Aust 1999; 170: 429-432.

18 Templeton DJ, Tyson BA, Meharg JP, et al. Aboriginal health worker screening for sexually transmissible infections and blood-borne viruses in a rural Australian juvenile correctional facility. Sex Health 2010; 7: 44-48.

19 Chen MY, Donovan B. Genital Chlamydia trachomatis infection in Australia: epidemiology and clinical implications. Sex Health 2004; 189-196.

20 Lewis D, Newton DC, Guy RJ, et al. The prevalence of Chlamydia trachomatis infection in Australia: a systematic review and metaanalysis. BMC Infect Dis 2012; 12: 113

21 Lee V, Tobin JM, Foley E. Relationship of cervical ectopy to chlamydia infection in young women. J Fam Plann Reprod Health Care 2006; 32: 104-106.

22 Grulich AE, de Visser RO, Smith AM, et al. Sex in Australia: knowledge about sexually transmissible infections and blood-borne viruses in a representative sample of adults Aust N Z J Public Health 2003; 27: 230-233.

23 Fairley CK, Vodstrcil LA, Read T. The importance of striving for greater efficiency. Sex Health 2011; 8: 3-4.

24 Guy R, Ward JS, Smith KS, et al. The impact of sexually transmissible infection programs in remote Aboriginal communities in Australia: a systematic review. Sex Health 9: 205-212.

25 Ward J, Guy R, Huang RL, et al. Rapid point-ofcare tests for HIV and sexually transmissible infection control in remote Australia: can they improve Aboriginal people's and Torres Strait Islanders' health. Sex Health 9: 109-112. 